\title{
Graphene Synthesis, Catalysis with Transition Metals and Their Interactions by Laser Photolysis
}

\author{
Bonex W Mwakikunga1,2 and Kenneth T Hillie ${ }^{1,3}$ \\ ${ }^{1}$ Council for Scientific and Industrial Research, \\ National Centre for Nano-structured Materials, Pretoria \\ ${ }^{2}$ Department of Physics and Biochemical Sciences, University of Malawi, \\ The Malawi Polytechnic, Chichiri, Blantyre, \\ ${ }^{3}$ Department of Physics, University of Free State, Bloemfontein, \\ 1,3 South Africa \\ ${ }^{2}$ Malawi
}

\section{Introduction}

This chapter introduces some facts about graphene, how it was discovered, how it has been realised by several approaches and how to get its identity. Its identity is seen either through cross-sectional TEM or through its unique signature in Raman spectra. We also briefly review bottom-up and top-down synthesis approaches that have led either to few layers or monolayer graphene. We discuss the photochemical mechanisms and process of the formation of graphene, graphene's catalysis of the vanadium oxide mono-layers, the defects leading to inorganic fullerenes of vanadium dioxide/pentoxide and the wrapping of these fullerenes in triangular graphene-like envelops. A general theory and review of $\mathrm{KrF}$ laser beam interaction with metallorganic liquids are given. A case study of laser beam - V-(OC $\left.\mathrm{OC}_{2} \mathrm{H}_{5}\right)_{3}$ interaction is presented and the subsequent formation steps for graphene, $\mathrm{V}_{2} \mathrm{O}_{5}$ layers and $\mathrm{V}_{2} \mathrm{O}_{5}$ fullerenes are outlined.

\subsection{Materials that should not exist}

More than 70 years ago, Landau and Peierls [1,2] argued that strictly two-dimensional (2D) crystals were thermodynamically unstable and could not exist. Their theory pointed out that a divergent contribution of thermal fluctuations in low-dimensional crystal lattices should lead to such displacements of atoms that they become comparable to inter-atomic distances at any finite temperature. The argument was later extended by Mermin [3] and is strongly supported by a number of experimental observations. Indeed, the melting temperature of thin films rapidly decreases with decreasing thickness, and they become unstable (segregate into islands or decompose) at a thickness of, typically, dozens of atomic layers. For this reason, atomic monolayers have so far been known only as an integral part of larger 3D structures, usually grown epitaxially on top of monocrystals with matching crystal lattices. Without such a 3D base, 2D materials were presumed not to exist until 2004, when the common wisdom was flaunted by the experimental discovery of graphene and other free- 
standing 2D atomic crystals (for example, single-layer boron nitride and half-layer BSCCO [4]). These crystals could be obtained on top of non-crystalline substrates, in liquid suspension (Fig. 1) and as suspended membranes. Importantly, the 2D crystals were found not only to be continuous but to exhibit high crystal quality. The latter is most obvious for the case of graphene, in which charge carriers can travel thousands of interatomic distances without scattering. With the benefit of hindsight, the existence of such one-atom-thick crystals can be reconciled with theory. Indeed, it can be argued that the obtained 2D crystallites are quenched in a metastable state because they are extracted from 3D materials, whereas their small size and strong interatomic bonds assure that thermal fluctuations cannot lead to the generation of dislocations or other crystal defects even at elevated temperature.

\subsection{What is graphene? Known facts about graphene}

Graphene is the name given to a flat monolayer of carbon atoms tightly packed into a twodimensional (2D) honeycomb lattice, and is a basic building block for graphitic materials of all other dimensionalities (Figure 2). It can be wrapped up into 0D fullerenes, rolled into 1D nanotubes or stacked into 3D graphite.

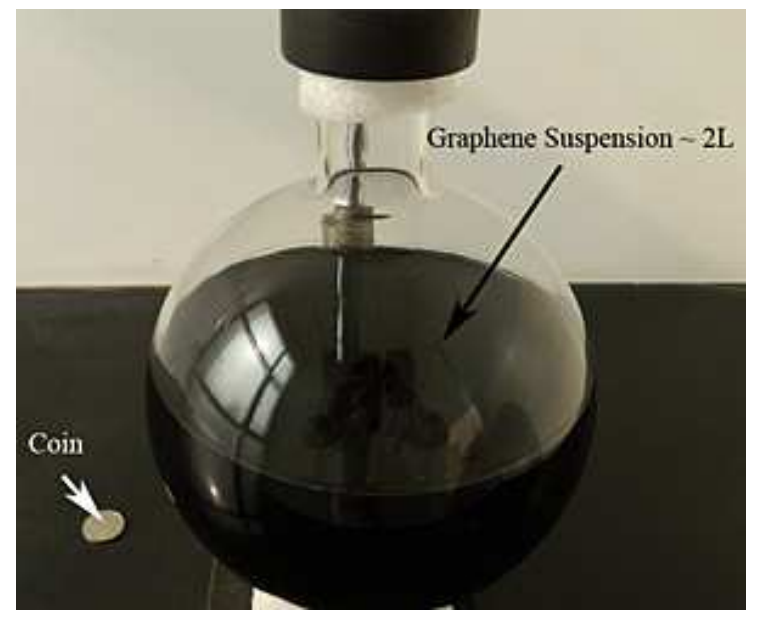

Fig. 1. How graphene suspension looks like

Theoretically, graphene (or "2D graphite") has been studied for sixty years and has been widely used for describing properties of various carbon-based materials. Forty years later, it was realized that graphene also provides an excellent condensed-matter analogue of $(2+1)$ dimensional quantum electrodynamics, which propelled graphene into a thriving theoretical toy model. On the other hand, although known as integral part of 3D materials, graphene was presumed not to exist in the free state, being described as an "academic" material and believed to be unstable with respect to the formation of curved structures such as soot, fullerenes and nanotubes. All of a sudden, the vintage model turned into reality, when free-standing graphene was unexpectedly found around 2004 by Novoselov and Geim [5] and, especially, when the follow-up experiments confirmed that its charge carriers were indeed massless Dirac fermions [6]. So, the graphene "gold rush" has begun. A complementary viewpoint is that the 
extracted 2D crystals become intrinsically stable by gentle crumpling in the third dimension on a lateral scale of $\approx 10 \mathrm{~nm}$. Such $3 \mathrm{D}$ warping observed experimentally leads to a gain in elastic energy but suppresses thermal vibrations (anomalously large in 2D), which above a certain temperature can minimize the total free energy.

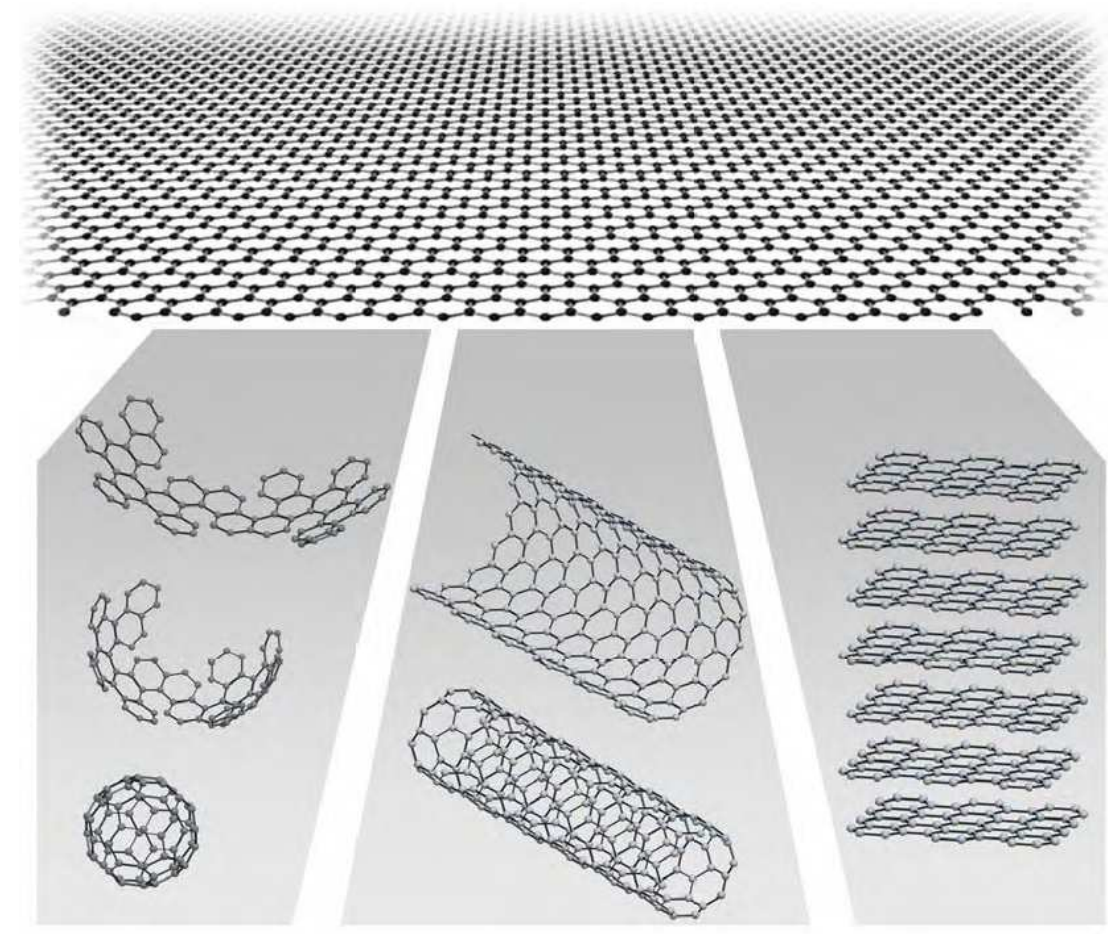

Fig. 2. Mother of all graphitic forms. Graphene is a 2D building material for carbon materials of all other dimensionalities. It can be wrapped up into 0D buckyballs, rolled into 1D nanotubes or stacked into 3D graphite [from: Geim and Novoselov, http://arxiv.org/ftp/cond-mat/papers/0702/0702595.pdf]

A single atomic plane is a 2D crystal, whereas 100 layers should be considered as a thin film of a 3D material. But how many layers are needed to make a 3D structure? For the case of graphene, the situation has recently become reasonably clear. It was shown that the electronic structure rapidly evolves with the number of layers, approaching the 3D limit of graphite already at 10 layers. Moreover, only graphene and, to a good approximation, its bilayer have simple electronic spectra: they are both zero-gap semiconductors (can also be referred to as zero-overlap semimetals) with one type of electrons and one type of holes. For 3 and more layers, the spectra become increasingly complicated: Several charge carriers appear, and the conduction and valence bands start notably overlapping. This allows one to distinguish between single-, double- and few- $(3$ to $<10)$ layer graphene as three different types of 2D crystals ("graphenes") [6].

Thicker structures should be considered, to all intents and purposes, as thin films of graphite. From the experimental point of view, such a definition is also sensible. The screening length in 
graphite is only $\approx 5 \AA$ (that is, less than 2 layers in thickness) and, hence, one must differentiate between the surface and the bulk even for films as thin as 5 layers. Earlier attempts to isolate graphene concentrated on chemical exfoliation. To this end, bulk graphite was first intercalated (to stage I) so that graphene planes became separated by layers of intervening atoms or molecules. This usually resulted in new 3D materials. However, in certain cases, large molecules could be inserted between atomic planes, providing greater separation such that the resulting compounds could be considered as isolated graphene layers embedded in a 3D matrix. Furthermore, one can often get rid of intercalating molecules in a chemical reaction to obtain a sludge consisting of restacked and scrolled graphene sheets. Because of its uncontrollable character, graphitic sludge has so far attracted only limited interest. There have also been a small number of attempts to grow graphene. The same approach as generally used for growth of carbon nanotubes so far allowed graphite films only thicker than $\approx 100$ layers. On the other hand, single- and few-layer graphene have been grown epitaxially by chemical vapour deposition of hydrocarbons on metal substrates and by thermal decomposition of SiC. Such films were studied by surface science techniques, and their quality and continuity remained unknown. Only lately, few-layer graphene obtained on $\mathrm{SiC}$ was characterized with respect to its electronic properties, revealing high-mobility charge carriers. An illustration of a few layers of graphene is given in Figure 3. Epitaxial growth of graphene offers probably the only viable route towards electronic applications and, with so much at stake, a rapid progress in this direction is expected. The approach that seems promising but has not been attempted yet is the use of the previously demonstrated epitaxy on catalytic surfaces (such as $\mathrm{Ni}$ or $\mathrm{Pt}$ ) followed by the deposition of an insulating support on top of graphene and chemical removal of the primary metallic substrate.

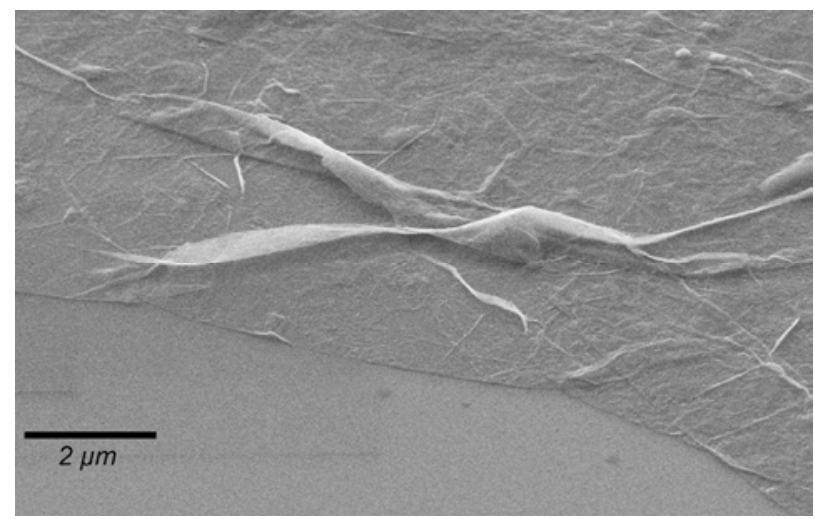

Fig. 3. A few layers of graphene seen by scanning electron microscopy [Taken from www. sineurop-nanotech.com/en/graphene.html Courtsey SINEUROP Nanotech GmbH, Stuttgart, Germany]

\subsection{How does one tell if it is graphene? Counting the number of graphene layers 1.3.1 Transmission electron microscopy (TEM )}

Transmission electron microscopy is a two-dimensional microscopy technique. It is difficult to probe the third dimension by this technique. The only way to measure the thickness of graphene layers is by performing cross-sectional TEM which can be accomplished by mounting the sample such that the electrons from the gun run parallel to the surface of the graphite layer. 


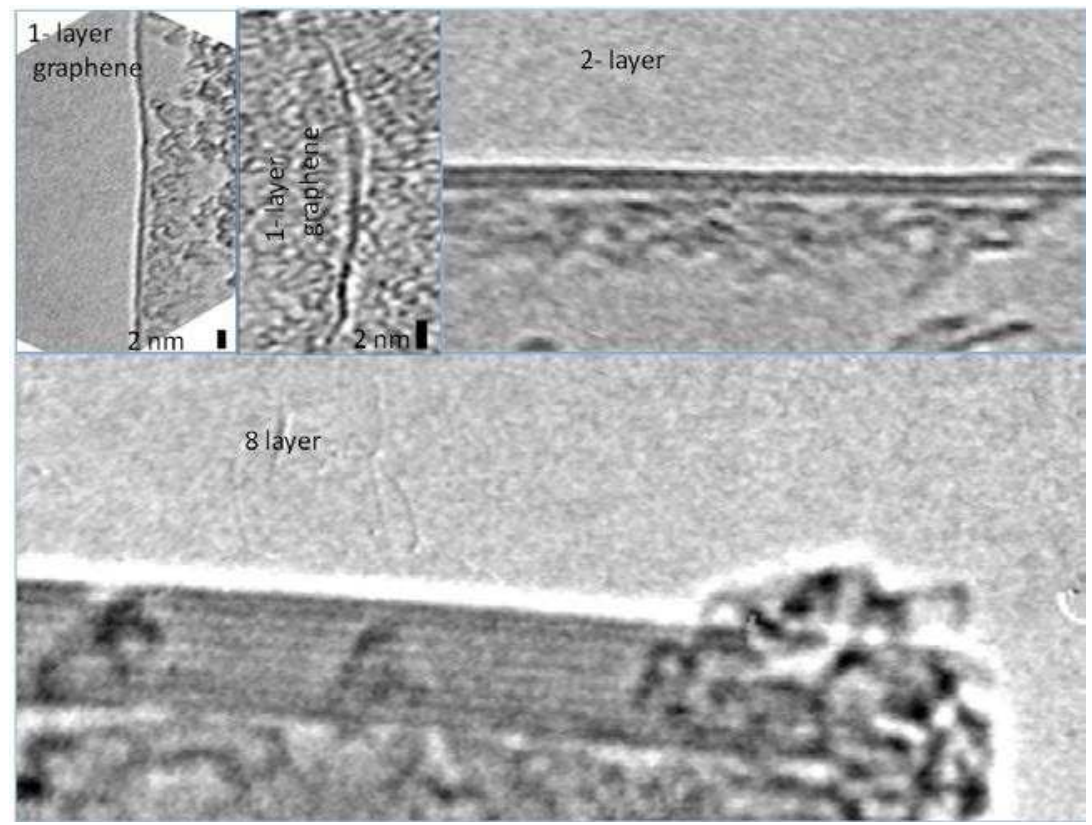

Fig. 4. Counting the number of layers of graphene by high resolution TEM (From A.C. Ferrari et al [7])

Naturally, graphene edges tend to fold and often show wrinkles in the sheet. Close analysis of the fold edge allows for the ability to count the number of layers.

\subsubsection{Atomic force microscopy}

By atomic force microscopy (AFM) technique, one is able to view the graphene layer in all the three dimensions. From many studies, AFM images for graphene will range from $0.5 \mathrm{~nm}$ to $1.5 \mathrm{~nm}$ depending on the chemical contrast between the graphene layer and the substrate. For this reason, determination of the thickness of monolayer of graphene by AFM has to be corroborated by other available techniques such as TEM as mentioned already.

\subsubsection{Raman spectroscopy}

Raman spectroscopy of carbon materials offers a very important versatility in distinguishing the structures carbon displays viz: amorphous carbon $(a-C)$, tetrahedrally amorphous carbon (ta-C), graphite, highly oriented pyrolytic graphite (HOPG), carbon nanotubes, carbon fullerens, diamond and now graphene. Since graphene is but a single layer of graphite, its Raman signature should contain most of the features that are contained in the graphite's Raman signature. However, there two distinct features that stand out in a monolayer graphene that one cannot see in even two-layer graphene: (1) the slight upshift of the $\mathrm{G}$ peak by about $5 \mathrm{~cm}^{-1}$ and (2) the enhancement of graphite's shoulder peak to secondorder D peak (named traditionally as $G^{\prime}$ ) to the expense of the main $G^{\prime}$ peak.

When excitation laser wavelength in the Raman spectrometer is changed from $514 \mathrm{~nm}$ to 633 $\mathrm{nm}$, the signatures become slightly noisy without much noticeable change in the phonon wave-numbers as illustrated in Fig 7. Also, the single $2690 \mathrm{~cm}^{-1}$ phonon from the one-layer 
graphene is replaced by a main phonon at $2710 \mathrm{~cm}^{-1}$ with the $2690 \mathrm{~cm}^{-1}$ becoming its shoulder in multi-layer graphite

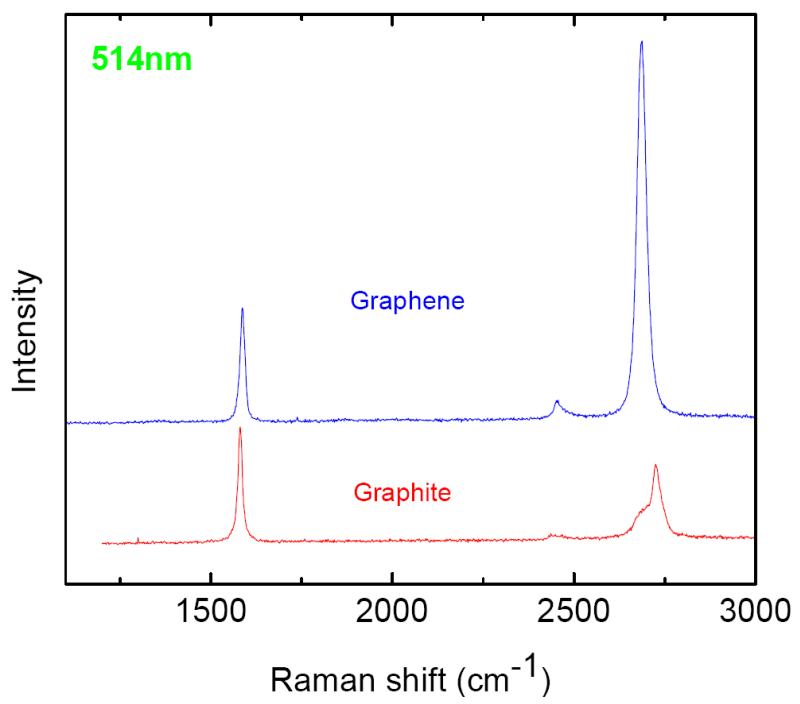

Fig. 5. The Raman signatures for graphene and graphite employing a $514 \mathrm{~nm}$ laser wavelength in the Raman spectrometer (From A.C. Ferrari et al [7])

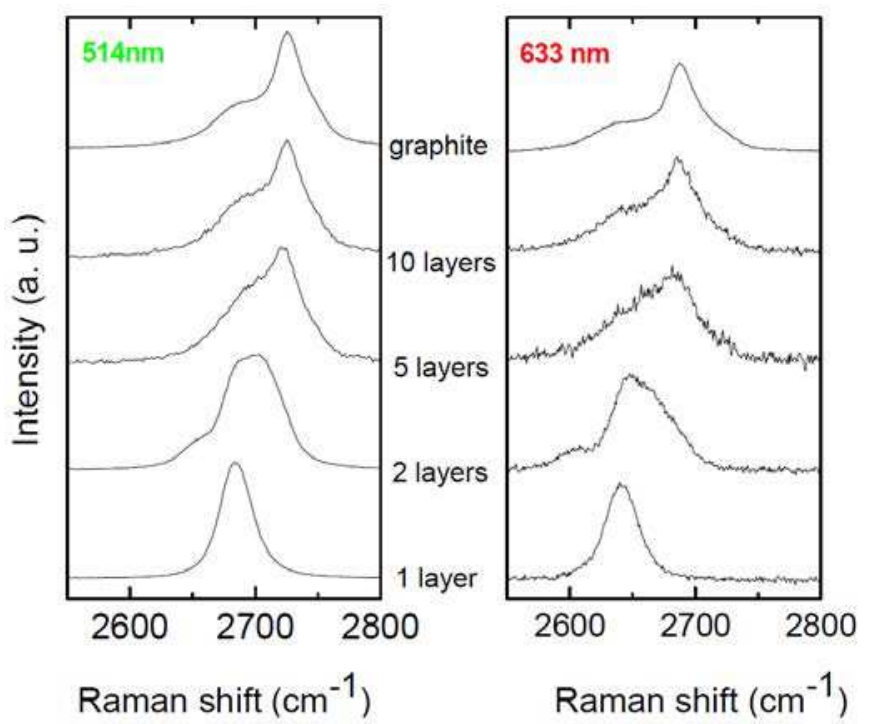

Fig. 6. Raman spectra under $514 \mathrm{~nm}$ and $633 \mathrm{~nm}$ laser wavelength excitation of the $\mathrm{G}^{\prime}$ for different number of layers showing the single $2690 \mathrm{~cm}^{-1}$ phonon from from the one-layer graphene replaced by a main phonon at $2710 \mathrm{~cm}^{-1}$ with the $2690 \mathrm{~cm}^{-1}$ becoming its shoulder in multi-layer graphite (From A.C. Ferrari et al [7]) 


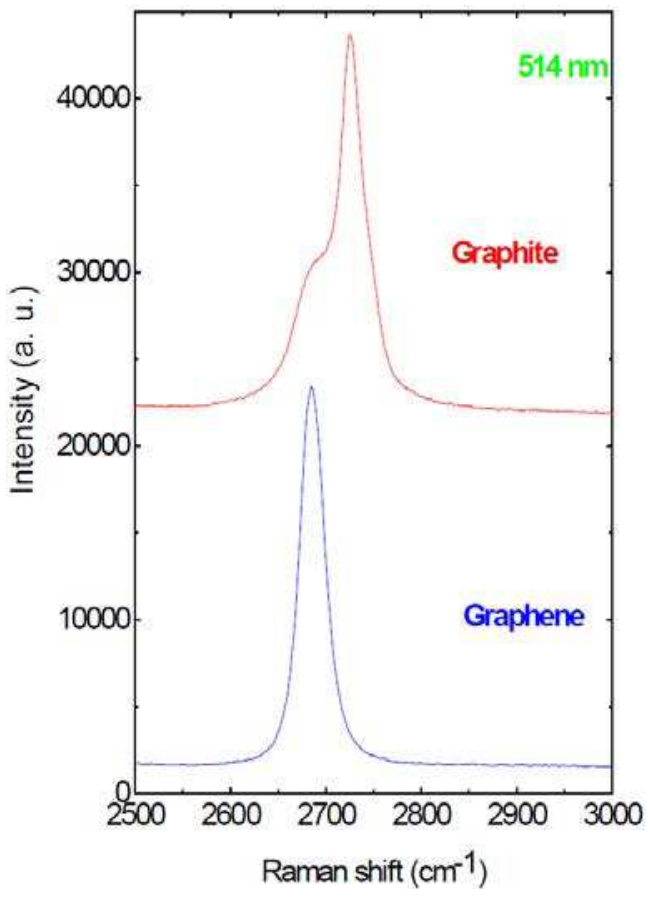

Fig. 7. The single $2690 \mathrm{~cm}^{-1}$ phonon from from the one-layer graphene replaced by a main phonon at $2710 \mathrm{~cm}^{-1}$ with the $2690 \mathrm{~cm}^{-1}$ becoming it shoulder in multi-layer graphite(From A.C. Ferrari et al [7])

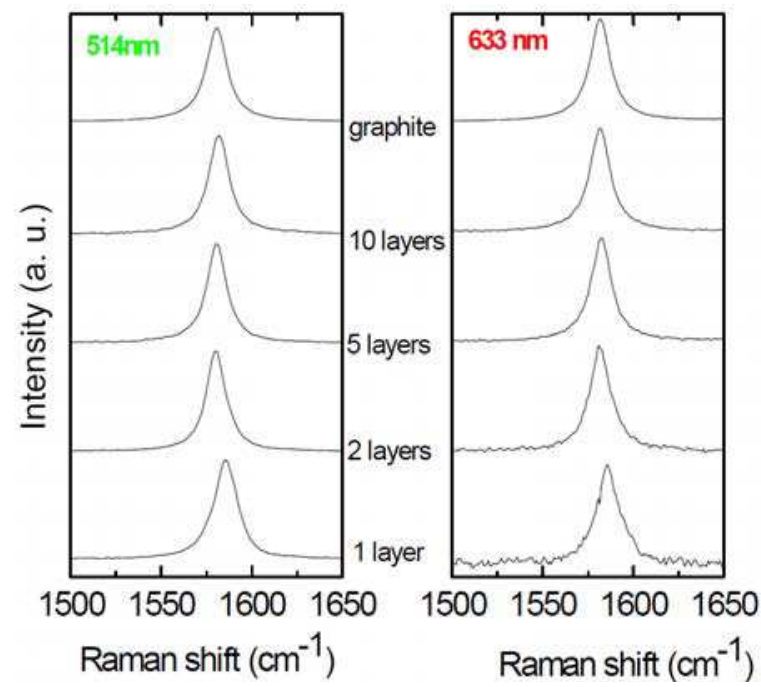

Fig. 8. The slight up-shift of the graphite $G$ peak as the number of grapheme layers decreases to one layer. (From A.C. Ferrari et al [7]) 


\section{Brief review on graphene synthesis}

\subsection{Top-down versus bottom-up approaches to the realisation of graphene}

In a top-down approach, graphene is derived from graphite contained in a pencil lead that we use in everyday life (Figure 9) by stripping layers from a bulk sample. Methods such as the Scotch tape stripping, ion sputtering, pulsed laser deposition, ball milling and arc discharge are all examples of top-down approaches.

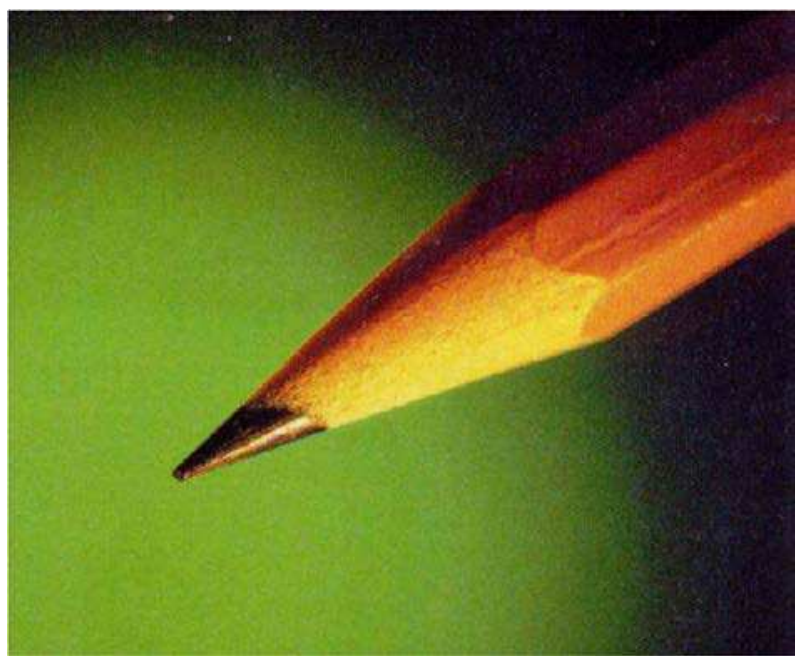

Fig. 9. Graphite in a pencil. When writing in pencil you are placing layers of grapheme on paper substrate. Invisible writings could be few layers or even monolayer of graphene.

(From A.C. Ferrari et al [7])

Bottom-up routes involve starting at atomic scale and building up atom by atom to the desired final size of the material. Synthesis routes such as chemical vapour deposition (CVD), wet chemistry or the so-called Fischer-Tropsch synthesis, ion implantation, pyrolysis can be regarded as examples of bottom-up approaches. We will review some of these approaches in the sections that follow with regard to the realisation of graphene.

\subsection{Chemical vapour deposition}

Chemical vapour deposition techniques involve, in general, the decomposition of fluid (gas and liquid sprays) at high temperature to form either thin films on substrates or powders through filters. There are many forms of CVD including: hot wire CVD, thermal CVD, plasma enhanced (PE) CVD, radio-frequency (RF) CVD, ultrasonic spray pyrolysis (USP) among many derivatives. A typical system is illustrated in Figure 10. Graphene synthesis by this method has been reported from around 2008 [8-21], that is, about four years after the discovery of single layer graphene by physical exfoliation. Table 1 summarizes some of the conditions for obtaining single to few layer graphene on various substrates employing the stipulated catalysts in each case. Note that the list is not exhaustive. Before $2000[19,20]$, only $\mathrm{C}_{14} \mathrm{~N}$ to $\mathrm{C}_{16} \mathrm{~N}$ (or $\mathrm{N}$ doped graphene) layers are reported. 


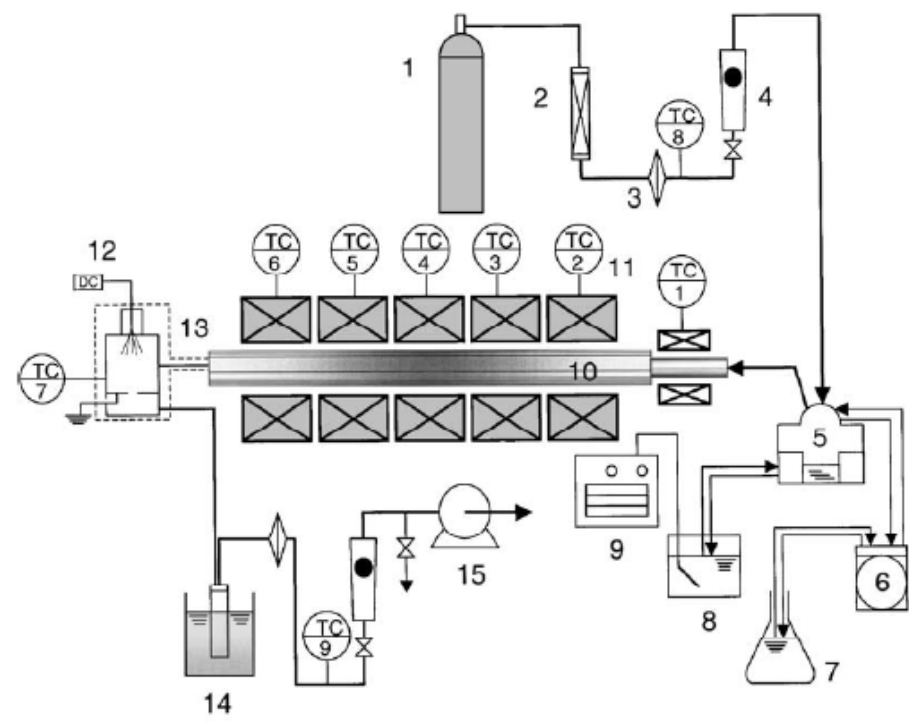

1. Air bomb

2. Packed column

3. Filter

4. Flowmeter

5. Ultrasonic nebulizer

6. Peristatic pump

7. Solution

8. Water bath

9. Immersion cooler

10. Reactor tube

11. Electric furnace

12. D.C. high voltage supply

13. Electrostatic precipitator

14. Cold trap

15. Vacuum pump

Fig. 10. Schematic illustration of a typical CVD system [From B W Mwakikunga PhD thesis, University of the Witwatersrand (2009)]

\begin{tabular}{|c|c|c|c|c|c|}
\hline Precursor & Temperature & Pressure & Catalyst & $\begin{array}{l}\text { Type of } \\
\text { CVD }\end{array}$ & References \\
\hline Hydrocarbons & & Std P & Bi-metallic & RF-CVD & $\begin{array}{l}\text { E. Dervishi } \\
2011\end{array}$ \\
\hline Hydrocarbons & $900-1000{ }^{\circ} \mathrm{C}$ & Std P & $\begin{array}{l}\text { c-sapphire, } \mathrm{Co} / \mathrm{SiO}_{2} \\
\text { and } \mathrm{H}_{2} \text { (annealing) }\end{array}$ & $\begin{array}{l}\text { Epitaxial } \\
\text { CVD }\end{array}$ & $\begin{array}{l}\text { H Ago et al } \\
2010\end{array}$ \\
\hline Methane & & & $\begin{array}{l}\mathrm{Ni} \text { and } \mathrm{Cu} \text { in } \\
\text { ammonia }\end{array}$ & & $\begin{array}{l}\text { Park et al } \\
2010\end{array}$ \\
\hline Ethylene & & & Bi-metallic & RF-CVD & $\begin{array}{l}\text { E. Dervishi } \\
2010\end{array}$ \\
\hline Methane and $\mathrm{H}_{2}$ & $850-1000 \circ \mathrm{C}$ & & Ni thin film & CVD & Lee et al 2010 \\
\hline $\begin{array}{l}\text { Iron tetra-pyridino- } \\
\text { porphyrazine }\end{array}$ & & & & Pyrolysis & Xu et al 2010 \\
\hline methane & & $\begin{array}{l}\text { Atm, } \\
\text { Torr } \\
\text { Vacuum }\end{array}$ & $\mathrm{Cu}$ & $\begin{array}{l}\text { APCVD } \\
\text { LPCVD } \\
\text { UHVCVD }\end{array}$ & $\begin{array}{l}\text { Bhaviripudi } \\
\text { et al } 2010\end{array}$ \\
\hline Methane on HOPG & & & $\mathrm{Fe}$ & & $\begin{array}{l}\text { Kholmanov } \\
2010\end{array}$ \\
\hline Methane & $1000 \mathrm{oC}$ & & $\begin{array}{l}\mathrm{Co} \text { on } \mathrm{MgO} \\
\text { Argon flow }\end{array}$ & & $\begin{array}{l}\text { Wang, } X \\
(2009)\end{array}$ \\
\hline Methane & $700 \mathrm{oC}$ & & $\mathrm{Fe}$ & PECVD & $\begin{array}{l}\text { Malesevic } \\
2008\end{array}$ \\
\hline Methane & $1400-1900$ oC & & $6 \mathrm{H} \mathrm{SiC}$ & PECVD & $\begin{array}{l}\text { Cambaz, } \\
\text { Z.G., (2008) }\end{array}$ \\
\hline
\end{tabular}

Table 1. A summary of some of the parameters for obtaining graphene by CVD 


\subsection{Arc discharge}

In the arc discharge technique, graphite rods are used as electrodes for high voltage arc-ing. At extremely high voltages between the electrodes that are separated by very small distances, very high electric fields can be produced leading to instantaneous sparks like in a welding process. The fall-out during the discharge process is the end product that contains the carbon nano-structures.

Volotskova et al [22] have reported on deterministic, single-step approach to simultaneous production and magnetic separation of graphene flakes and carbon nanotubes. In this arc discharge process, by employing magnetic fields, nanotubes and graphene are deposited in different areas. These results are very relevant to the development of commerciallyviable, single-step production of bulk amounts of high-quality graphene. Also Li et al [23] have reported the existence of double layered graphene sheets in their arc discharge "debris".

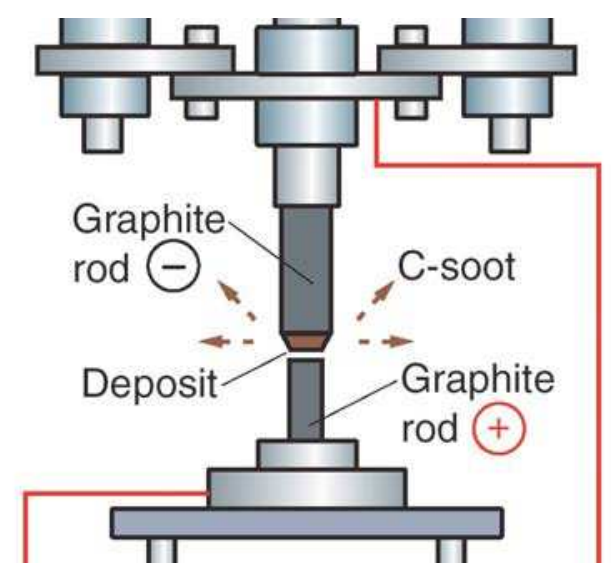

Fig. 11. A typical arc discharge system [mrsec.wisc.edu/.../images/nanotubes/arc.jpg]

\subsection{Fischer-Tropsch synthesis}

The Fischer-Tropsch process (or Fischer-Tropsch Synthesis) is a set of chemical reactions that convert a mixture of carbon monoxide and hydrogen into liquid hydrocarbons. The process, a key component of gas to liquids technology, produces a petroleum substitute, typically from coal, natural gas, or biomass for use as synthetic lubrication oil and as synthetic fuel. The F-T process has received intermittent attention as a source of low-sulfur diesel fuel and to address the supply or cost of petroleum-derived hydrocarbons.

The Fischer-Tropsch process involves a series of chemical reactions that lead to a variety of hydrocarbons. Useful reactions give alkanes, $(2 n+1) \mathrm{H}_{2}+\mathrm{nCO} \rightarrow \mathrm{C}_{n} \mathrm{H}_{(2 n+2)}+\mathrm{nH}_{2} \mathrm{O}$, where $\mathrm{n}$ is a positive integer. The formation of methane $(n=1)$ is generally unwanted. Most of the alkanes produced tend to be straight-chain alkanes, although some branched alkanes are also formed. In addition to alkane formation, competing reactions result in the formation of alkenes, as well as alcohols and other oxygenated hydrocarbons. Usually, only relatively small quantities of these non-alkane products are formed, although catalysts favoring some of these products have been developed. 


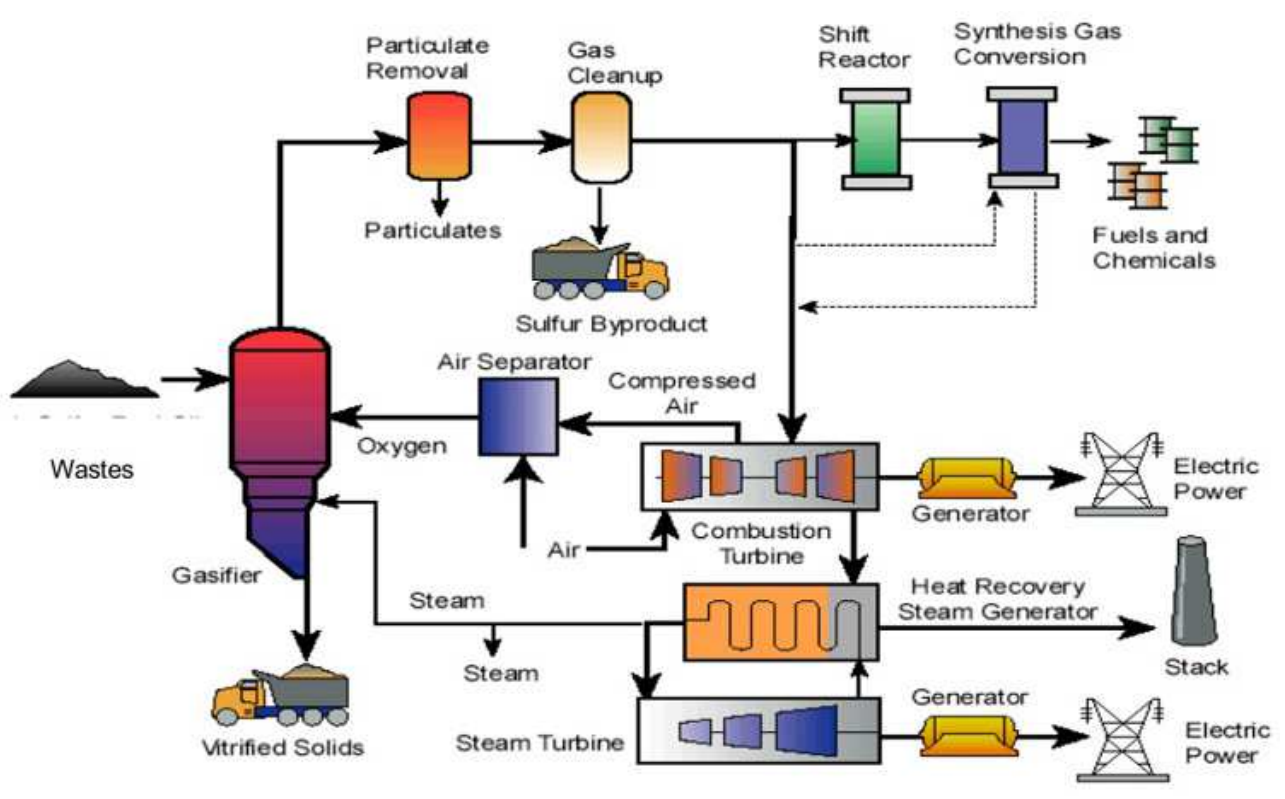

Fig. 12. An illustration of the Fischer-Tropsch synthesis [www.rccostello.com/copure.html]

Recently [24], Fischer-Tropsch Synthesis (FTS) reactions have suggested possibility to obtain carbon and $\mathrm{H}_{2} \mathrm{O}$ rather than alkanes and $\mathrm{H}_{2} \mathrm{O}$ through the reaction $(2 n+1) \mathrm{H}_{2}+$ $\mathrm{nCO} \rightarrow \mathrm{C}$ (graphene) $+\mathrm{nH}_{2} \mathrm{O}$ when the catalysis and other parameters are varied. For instance, the deactivation of a $20 \mathrm{wt} \% \mathrm{Co} / \mathrm{\gamma}-\mathrm{Al}_{2} \mathrm{O}_{3}$ catalyst during the FTS at $240{ }^{\circ} \mathrm{C}$, 20 bar, and a $\mathrm{H}_{2}$ :CO ratio of 2 was studied in a fixed-bed micro-reactor [Fei]. The $\mathrm{CO}$ conversion had reduced by $30 \%$ after $200 \mathrm{~h}$, and both carbidic and polyaromatic carbon species could be detected on the catalyst using a combination of TemperatureProgrammed Hydrogenation (TPH), X-ray Photoelectron Spectroscopy (XPS) and High Resolution Transmission Electron Microscopy (HRTEM). Using Density Functional Theory (DFT), the relative stability of different types of deposited carbon on the Co catalyst was evaluated. Extended layers of graphene were the most stable form, followed by a $4 \mathrm{~g}$ surface carbide phase initiating from the step edges. Both are more stable than surface $\mathrm{CH}_{2}$ groups by 99 and $79 \mathrm{~kJ} / \mathrm{mol}$.

Also Swart et al [25] have studied the possible catalyst deactivation mechanisms in the FTS synthesis of graphene overlayer by elucidating the adsorption of graphene on the fcc $\mathrm{Co}(111)$ surface. A chemical interaction between the graphene sheet and the cobalt surface was observed as evidenced by the partial DOS and Bader charge analysis. The adsorption energy was found to be small when normalized per carbon atom, but becoming large for extended graphene sheets. Graphene removal from the surface via lifting or sliding was considered. The energy barrier for sliding a graphene sheet is lower than the barrier for lifting, but the energy barriers become significant when placed into the context of realistic catalytic surfaces in the nano-meter range. 
Also Nolan et al [26] have deposited graphene on metal catalysts by this method. Carbon formed from $\mathrm{CO}$ in $\mathrm{CO}_{2}$ at around $500^{\circ} \mathrm{C}$ deposited as nanotubes and encapsulating carbons on a supported $\mathrm{Ni}$ catalyst without $\mathrm{H}_{2}$ or as filaments if $\mathrm{H}_{2}$ was present. By a thermodynamic model, they explained how hydrogen in low concentrations controls filament morphology and why equilibrium is shifted from that for graphite during carbon deposition. Carbon deposition reaction rates at low carbon activity in the absence of hydrogen were reported. When hydrogen was present, a series of hydrocarbons formed, as in fuel synthesis (Fischer-Tropsch) chemistry. Surface vinyl species that have been recently shown to be intermediates in Fischer-Tropsch chemistry also polymerized to form graphene. The formation of vinyls from $\mathrm{CO}$ and $\mathrm{H}$ via surface alkyls occurred at a greater rate than methane formation when the supply of hydrogen was limited. Hydrogen from the bulk catalyst metal (not surface adsorbed) hydrogenates the surface alkyls, indicating that hydrogen solubility may control the metal-catalyzed formation of various hydrocarbons and eventually solid graphitic carbon.

\subsection{High Temperature High Pressure technique}

Graphene has been produced by a high pressure-high temperature (HPHT) growth process from the natural graphitic source material by utilising the molten Fe-Ni catalysts for dissolution of carbon [27]. The method may lead to a more reliable graphene synthesis and facilitate its purification and chemical doping.

\subsection{Sputtering}

During the co-sputtering of $\mathrm{C}$ and $\mathrm{Cu}$ into a carbon matrix [28], a demixing (segregation) occurs of the carbon and copper species due to their very low solubilities that leads to the formation of nanometric copper precipitates homogeneously distributed in a more or less graphitic matrix. These precipitates have an elongated shape in the direction of the thin film growth. When the deposition was performed at $273 \mathrm{~K}$ for copper atomic concentrations $\mathrm{C}_{\mathrm{Cu}}>55 \%$, as well as for all thin films synthesized at $573 \mathrm{~K}$ whatever the $\mathrm{C}_{\mathrm{Cu}}$ value, the formation of graphene layers parallel to the surface of the copper precipitates was observed so that an encapsulation of the $\mathrm{Cu}$ aggregates in carbon cages occurs.

\subsection{Wet chemistry and sonication}

Graphene-like carbon sheets can be synthesized, for instance, from adamantane in the solution phase at ambient temperature. Adamantane, $\mathrm{C}_{10} \mathrm{H}_{16}$, has a tetracyclic ring structure with four cyclohexanes in chair conformation. The two dimensional carbon structures have been obtained by introducing ferrocene as the catalyst precursor and adamantane as the carbon source under sonication [29], proving that cyclohexane structures in adamantane can serve as a building block for graphene formation. The synthesized carbon sheets were characterized and confirmed by X-ray diffraction, high-resolution electron microscopy and atomic force microscopy.

Also, nanostructured $\mathrm{CN}_{\mathrm{x}}$ thin films were prepared by supersonic cluster beam deposition (SCBD) [30]. Films containing bundles of well-ordered graphene multilayers, onions and nanotubes embedded in an amorphous matrix were grown alongside purely amorphous films by changing the deposition parameters. Graphitic nanostructures were synthesized without using metallic catalysts. 


\subsection{Unzipping of SWCNT into monolayer graphene}

A very ingenious idea on realising a monolayer graphene by unzipping single wall carbon nanotubes has been reported recently [31]. At this scale, the unzipping, has been accomplished by harsh acids and the right thermodynamic conditions. A computer generated illustration of the unzipping process is illustrated in Figure 12.

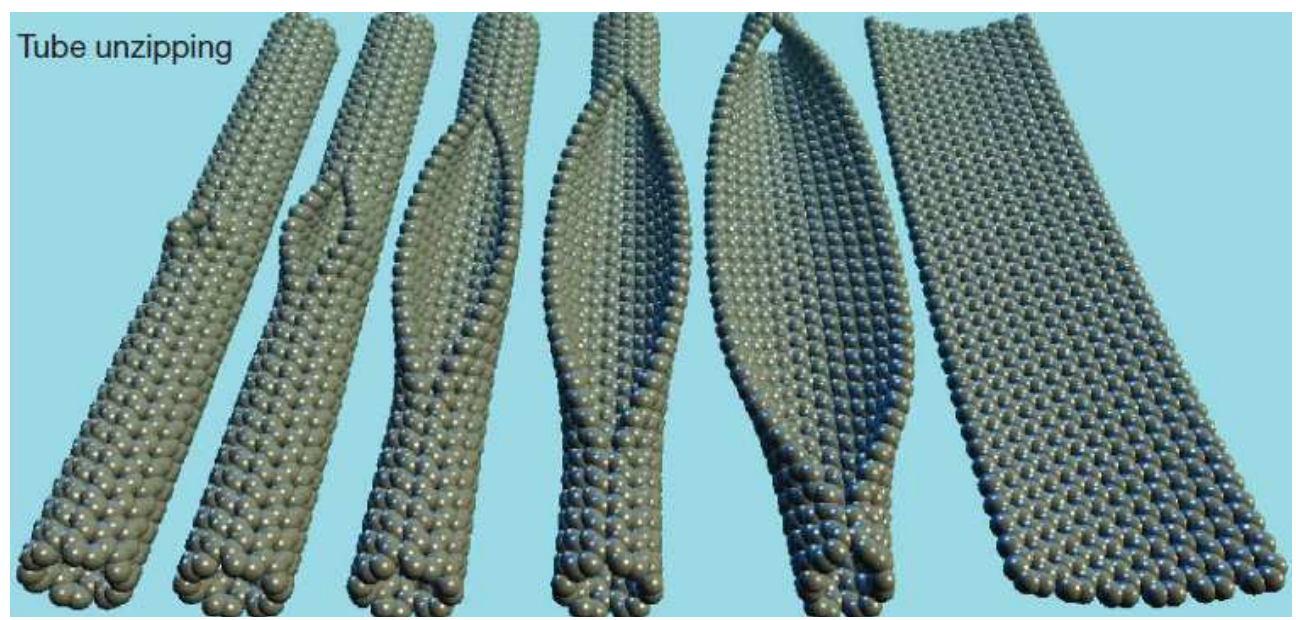

Fig. 12. Modelling illustration of the SWCNT unzipped into monolayer graphene [31]

\subsection{Carbon implantation into catalyst substrates}

Ion implantation method for large-scale synthesis of high quality graphene films with controllable thickness has been demonstrated [32,33]. Thermally annealing polycrystalline nickel substrates that have been ion implanted with carbon atoms results in the surface growth of graphene films whose average thickness is controlled by implantation dose. The implantation synthesis method can be generalized to a variety of metallic substrates and growth temperatures, since it does not require a decomposition of chemical precursors or a solvation of carbon into the substrate.

\section{Graphene by laser solution photolysis}

Laser synthesis methods have been of particular interest [34, 35]. The coherent, intense and almost monochromatic laser light allows it to be tuned to selectively dissociate specific bonds in a precursor molecule either by resonance between the laser frequency and the bond's natural frequency or via multi-photon absorption. This leads to products that can be unique and different from those obtained by traditional thermal deposition techniques. In this work, we followed a process called laser solution photolysis (LSP) that has been used previously to obtain FePt ultra-fine powders [36]. Organo-metallic 
precursors containing $\mathrm{Fe}$ and $\mathrm{Pt}$, respectively were employed in the presence of a polymer. The polymer was employed to reduce agglomeration of the nano-particles produced. Further examples of the technique include, gold nanoparticles produced by UV light irradiation of gold chloride [37-39], iron-based nanoparticles produced by utilising UV light absorbing ferrocene and iron(II) acetylacetonate [40,41] and laser ablation in a solid- liquid interface [42, 43].

In a study where metal ethoxide precursors, which were produced from metal chlorides reacted with ethanol, were employed in conjunction with the $\mathrm{KrF}$ laser at a wavelength of $248 \mathrm{~nm}$ to produced not only quantum dots but also graphene layers.

Triangular envelope-like structures of about $400 \mathrm{~nm}$ on each side of the triangle are the predominant polymorphs. The triangles are thin layers of $\mathrm{VO}_{\mathrm{x}}$ with an interplanar spacing of $3.75 \AA$ as shown in Fig. 13. Observed at higher magnification, the layers were found to be envelopes containing spherical nano-particles with an average size of $6 \mathrm{~nm}$. These $\mathrm{VO}_{x}$ quantum dots which can be solid (multi-walled) spheres or $\mathrm{VO}_{\mathrm{x}}$ fullerenes are found to have the same size distribution.
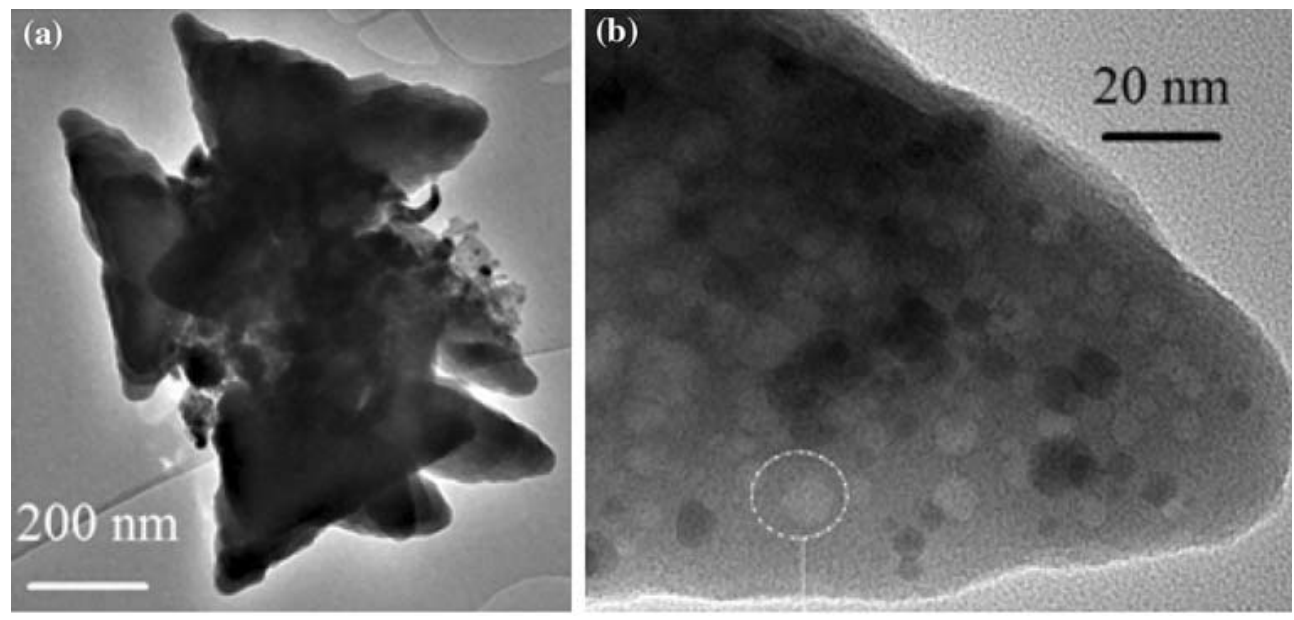

Fig. 13. (a) Low magnification TEM of the triangular envelopes of $\mathrm{VO}_{x},(b)$ one pocket at higher magnification, showing the small voids and solid spheres. The spheres have been found to be inorganic fullerenes of $\mathrm{VO}_{\mathrm{x}}$ segregated from graphene sheet that forms the envelope [52].

The strong and broad absorption peak at $598 \mathrm{~cm}^{-1}$ with its shoulder at $730 \mathrm{~cm}^{-1}$ can be assigned to the O-W-O stretching vibrations in the WO3 structure, whereas the $916 \mathrm{~cm}^{-1}$ peak corresponds to the $\mathrm{W}=\mathrm{O}$ surface stretching modes due to dangling oxygen bonds. The red-shift from the Raman allowed $960 \mathrm{~cm}^{-1}$ to the IR allowed $916 \mathrm{~cm}^{-1}$ could be due to the loading of carbon on these bonds. Carbon doping is confirmed by the presence of the peaks assigned to the $\mathrm{C}-\mathrm{O}$ bonding at 1,000 and 1,054 $\mathrm{cm}^{-1}$; these could not be observed in Raman 


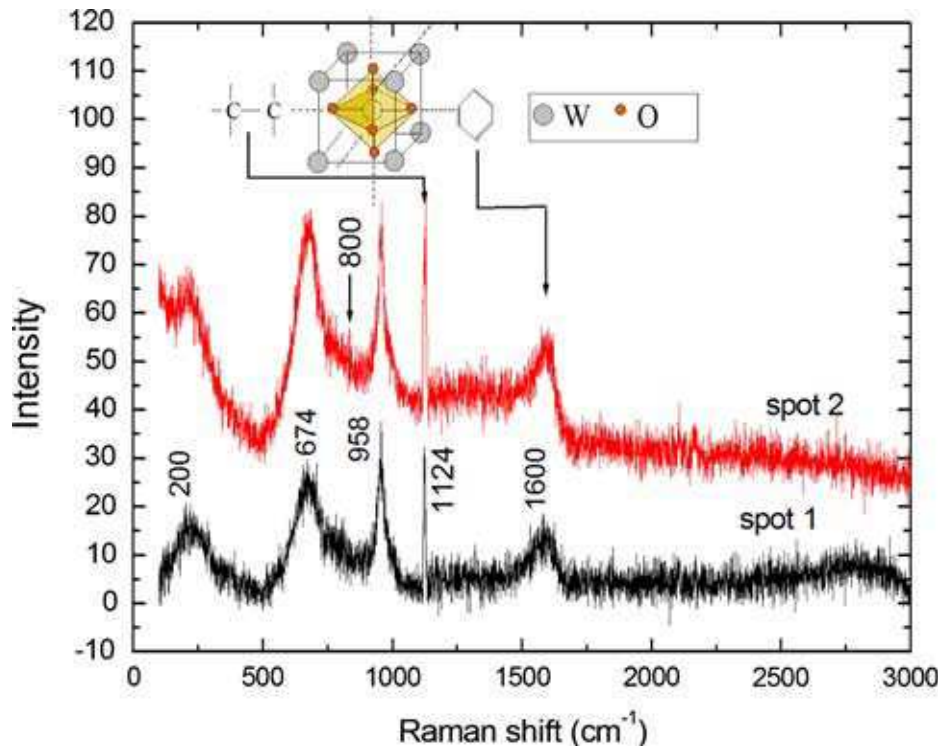

Fig. 14. Raman spectra of metal oxide QD-functionalised graphene. The G peak at $1600 \mathrm{~cm}^{-1}$ and the $\mathrm{G}^{\prime}$ at $2700 \mathrm{~cm}^{-1}$ on spot 1 are signatures from graphene layers. The rest of the peaks are from the metal oxides $\left(\mathrm{VO}_{2}\right.$ and $\left.\mathrm{WO}_{3}\right)$ [52]

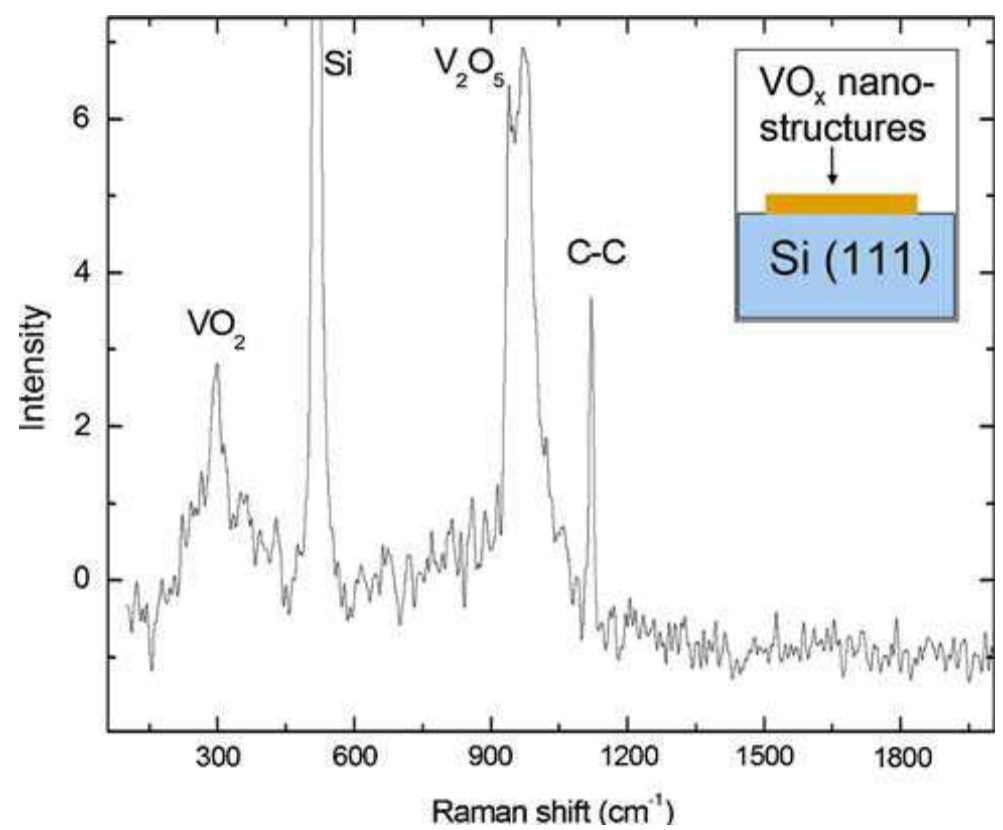

Fig. 15. Raman spectrum of inorganic fullerenes of $\mathrm{VO}_{\mathrm{x}}$ nanostructures [52] 
spectroscopy for reasons not established yet. The 1,600 $\mathrm{cm}^{-1}$ phonon frequency assigned to the perfect graphite's aromatic carbon ring is confirmed by FTIR as previously seen in Raman spectroscopy. The group of absorption peaks from 3,000 to 3,550 $\mathrm{cm}^{-1}$ have previously been assigned to $\mathrm{OH}$ bonds which suggest that some terminal oxygen atoms in the $\mathrm{WO}_{3}$ structure are not only bonded to the carbon aromatic rings but also to hydrogen. No C-H bonds were found by FTIR.

Raman spectroscopy of these structures supports the fact that there exists mixed valence of $\mathrm{V}^{4+}$ (signified by the $300 \mathrm{~cm}^{-1}$ phonon which is an undertone of the main $600 \mathrm{~cm}^{-1}$ peak which in these samples is masked by the strong $\mathrm{Si}-\mathrm{Si}$ background noise from the substrate at $520 \mathrm{~cm}^{-1}$ ) and $\mathrm{V}^{5+}$ from $930-970 \mathrm{~cm}^{-1}$. The peak at 1,120 $\mathrm{cm}^{-1}$ suggests the presence of $\mathrm{C}-\mathrm{C}$ bonds in the $\mathrm{VO}_{2} / \mathrm{V}_{2} \mathrm{O}_{5}$ structure. As opposed to the carbon modified $\mathrm{WO}_{3}$ nano-platelets which showed aromatic carbon apart from C-C bonds, Raman spectroscopy showed no aromatic rings in $\mathrm{VO}_{2} / \mathrm{V}_{2} \mathrm{O}_{5}$ triangular envelopes.

\section{Possible mechanism of formation of the triangular envelopes made out of graphene sheets and $\mathrm{VO}_{\mathrm{x}}$ inorganic fullerenes}

Since the discovery of carbon nano-tube structure in the early 1980s, Tenne and co-workers also reported similar structures in $\mathrm{WSe}_{2}$ and $\mathrm{MoS}_{2}$ [46]. The argument was that metal chalcogenides and oxides are also capable of arranging their unit cells in a hexagonal close packing as in carbon, thereby forming a layer of atoms whose edges leave dangling bonds. These bonds cause intense attractive forces which compel the layer to fold on itself into various shapes such as tubes, scrolls and rods. Formation of fullerenes is due to defects which are found to be pentagonal, rectangular and triangular bonds, which are possible in all transition metal compounds. Different processes of formation of, for instance, $\mathrm{V}_{2} \mathrm{O}_{5}$ capsules [47, 48] have led authors to suggest various mechanisms. We suggest that the formation of our triangular envelopes/capsules starts with the formation of closely packed hexagonal 2-D layers when the $\mathrm{VO}_{\mathrm{x}}$ is subjected to the laser beam. This assumption is based on the known experimental and theoretical facts from computer modelling that $\mathrm{V}_{2} \mathrm{O}_{5}$ is capable of wrapping into $\mathrm{V}_{2} \mathrm{O}_{5}$ nano-tubes [49] either as a zig-zag framework or in an arm chair structure [50]. It is also known that a mixture of $\mathrm{V}^{4+}$ and $\mathrm{V}^{5+}$ in $\left(\mathrm{V}^{\mathrm{IVO}}\right)$ [ $\left.\mathrm{V}^{\mathrm{O}} \mathrm{O}_{4}\right]_{.0 .5}\left[\mathrm{C}_{3} \mathrm{~N}_{2} \mathrm{H}_{12}\right]$ can lead to a layered structure [51]. The organic layer intercalates the inorganic counterpart with the latter containing square pyramids formed by $\mathrm{V}^{4+}$ ions and tetrahedral pyramids formed by $\mathrm{V}^{5+}$ ions. On this layer are randomly scattered fullerenes of the same material which have self-assembled under the same laser beam. These fullerenes together with dangling bonds on the layer periphery exert intense attractive forces which cause the layer to fold on itself in a certain pattern. A schematic cartoon of the possible formation of the $\mathrm{VO}_{2} / \mathrm{V}_{2} \mathrm{O}_{5}$ triangular envelops that encapsulate the $\mathrm{VO}_{2} / \mathrm{V}_{2} \mathrm{O}_{5}$ QDs and the $\mathrm{VO}_{2} / \mathrm{V}_{2} \mathrm{O}_{5}$ fullerenes are shown in Fig. 7. A hexagonal packing in a zig-zag fashion ends up having arm-chair structure dangling bonds in the periphery of the hexagon. The dangling bonds and the van der Waal's forces from the particles sitting on the surface compel this sheeting to wrap on itself from a hexagon, through intermediate stages, into a triangular envelope. The foldings are along arm-chair structure on two sides of the triangle AEC (sides $\mathrm{AC}$ and EC in Fig. 16 (a)) and along a zig-zag structure on the third side of the triangle (side $\mathrm{AE})$. 


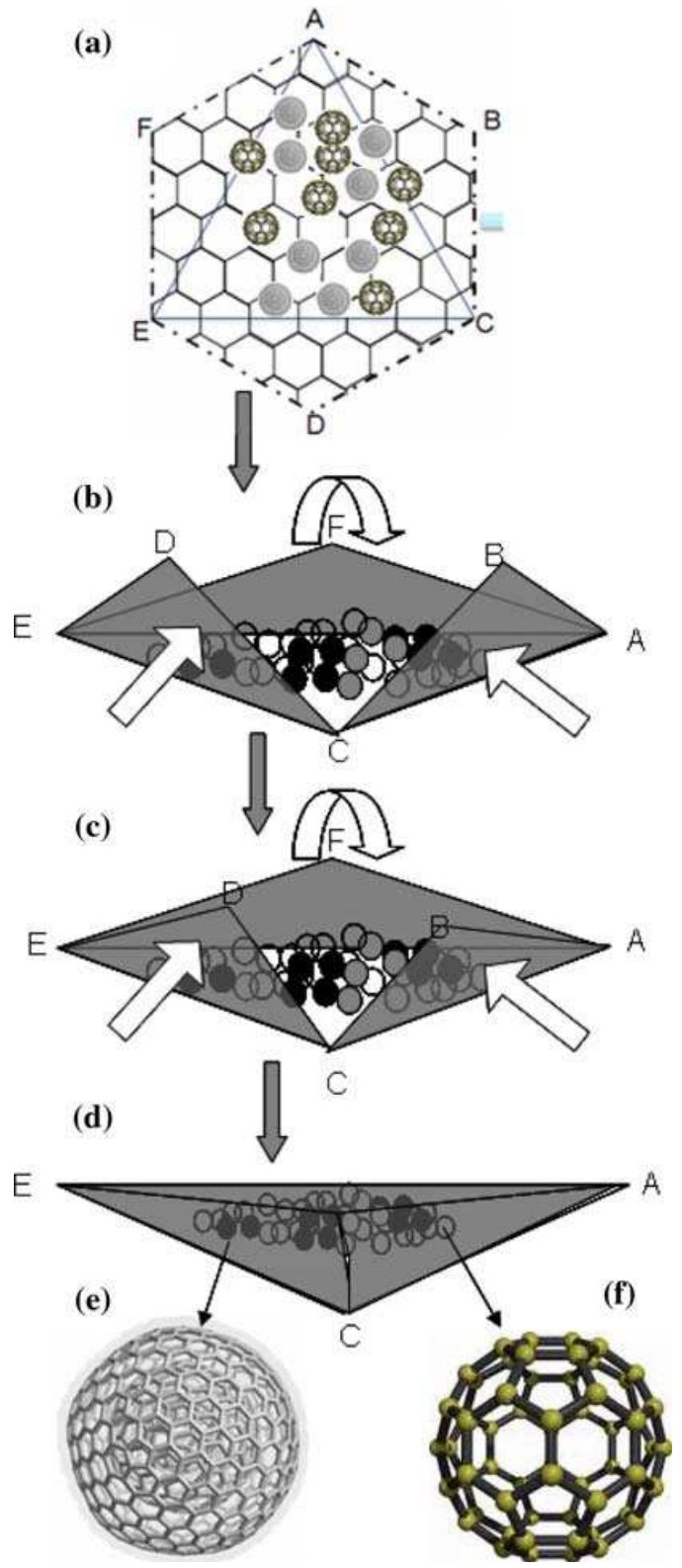

Fig. 16. A schematic representation of how the triangular envelops of graphene sheets as well as VOx sheets form (a) a hexagonally packed layer of V2O5/VO2 with some QDs of same material scattered randomly on it (b) the layer folds along zigzag $\mathrm{AE}$, armchair $\mathrm{EC}$ and armchair AC of triangle AEC (c) the folding of triangular flaps $\mathrm{ABC}, \mathrm{CDE}$ and EDF progresses until (d) the triangular envelop AEC is formed. The enveloped spherical particles are either (e) multi-walled $\mathrm{V}_{2} \mathrm{O}_{5} / \mathrm{VO}_{2}$ fullerenes or (f) single walled $\mathrm{V}_{2} \mathrm{O}_{5} / \mathrm{VO}_{2}$ fullerenes [52] 


\section{Conclusion}

We have presented the known facts about graphene and shown the identification methods by Raman spectroscopy and TEM. We have also presented a review of the most recent efforts to move away from the Scotch tape techniques (first discovered by Geim and Novoselov in 2004) to large scale routes towards the synthesis of graphene. We have shown how graphene and graphene-like layers are produced in laser solution photolysis of organo-metallic solutions and how both the inorganic fullerenes and graphene layers are produced and interact with each other. A mechanism for the wrapping of such particles by a graphene sheet is also discussed.

\section{References}

[1] Peierls, R. E. Quelques proprietes typiques des corpses solides. Ann. I. H. Poincare 5, 177222 (1935).

[2] Landau, L. D. Zur Theorie der phasenumwandlungen II. Phys. Z. Sowjetunion, 11, 26-35 (1937).

[3] Mermin, N. D. Crystalline order in two dimensions. Phys. Rev. 176, 250-254 (1968)

[4] Novoselov, K. S. et al. Two-dimensional atomic crystals. Proc. Natl Acad. Sci. USA 102, 10451-10453 (2005)

[5] Novoselov, K. S. et al. Electric field effect in atomically thin carbon films. Science 306, 666-669 (2004).

[6] Novoselov, K. S. et al. Two-dimensional gas of massless Dirac fermions in graphene. Nature 438, 197-200 (2005).

[7] A. C. Ferrari,1, ${ }^{*}$ J. C. Meyer,2 V. Scardaci,1 C. Casiraghi,1 M. Lazzeri,3 F. Mauri,3 S. Piscanec,1 D. Jiang,4, K. S. Novoselov,4 S. Roth,2 and A. K. Geim4, Raman Spectrum of Graphene and Graphene Layers, Phys. Rev. Lett. 97, 187401 (2006)

[8] Dervishi, E., Li, Z., Shyaka, J., Watanabe, F., Biswas, A., Umwungeri, J.L., Courte, A., Biris, A.S., The role of hydrocarbon concentration on the synthesis of large area few to multi-layer graphene structures, Chemical Physics Letters 501 (4-6), 390-395 (2011)

[9] Ago, H., Ito, Y., Mizuta, N., Yoshida, K., Hu, B., Orofeo, C.M., Tsuji, M., Mizuno, S., Epitaxial chemical vapor deposition growth of single-layer graphene over cobalt film crystallized on sapphire, ACS Nano 4 (12), 7407-7414 (2010)

[10] Park, H.J., Skákalová, V., Meyer, J., Lee, D.S., Iwasaki, T., Bumby, C., Kaiser, U., Roth, S., Growth and properties of chemically modified grapheme, Physica Status Solidi (B) Basic Research 247 (11-12), pp. 2915-2919 (2010)

[11] Dervishi, E., Li, Z., Shyaka, J., Watanabe, F., Biswas, A., Umwungeri, J.L., Courte, A., Biris, A.S., Large area graphene sheets synthesized on a bi-metallic catalyst system, Nanotechnology 2010: Advanced Materials, CNTs, Particles, Films and Composites - Technical Proceedings of the 2010 NSTI Nanotechnology Conference and Expo, NSTI-Nanotech 2010 1, 234-237 (2010)

[12] Lee, B.-J., Yu, H.-Y., Jeong, G.-H., Controlled synthesis of monolayer graphene toward transparent flexible conductive film application, Nanoscale Research Letters 5 (11), 1768-1773 (2010)

[13] Xu, Z., Li, H., Cao, G., Cao, Z., Zhang, Q., Li, K., Hou, X., (...), Cao, W. Synthesis of hybrid graphene carbon-coated nanocatalysts, Journal of Materials Chemistry 20 (38), pp. 8230-8232 (2010) 
[14] Bhaviripudi, S., Jia, X., Dresselhaus, M.S., Kong, J., Role of kinetic factors in chemical vapor deposition synthesis of uniform large area graphene using copper catalyst, Nano Letters 10 (10), pp. 4128-4133 (2010)

[15] Kholmanov, I.N., Cavaliere, E., Cepek, C., Gavioli, L., Catalytic chemical vapor deposition of methane on graphite to produce graphene structures, Carbon 48 (5), pp. 1619-1625 (2010)

[16] Wang, X., You, H., Liu, F., Li, M., Wan, L., Li, S., Li, Q., (...), Cheng, J., Large-scale synthesis of few-layered graphene using CVD, Chemical Vapor Deposition 15 (1-3), 53-56 (2009)

[17] Malesevic, A., Vitchev, R., Schouteden, K., Volodin, A., Zhang, L., Tendeloo, G.V., Vanhulsel, A., Haesendonck, C.V., Synthesis of few-layer graphene via microwave plasma-enhanced chemical vapour deposition, Nanotechnology 19 (30), art. no. 305604 (2008)

[18] Cambaz, Z.G., Yushin, G., Osswald, S., Mochalin, V., Gogotsi, Y., Noncatalytic synthesis of carbon nanotubes, graphene and graphite on $\mathrm{SiC}$, Carbon 46 (6), pp. 841-849 (2008)

[19] Nakajima, T., Koh, M., Takashima, M., Electrochemical behavior of carbon alloy CxN prepared by CVD using a nickel catalyst, Electrochimica Acta 43 (8), 883-891 (1997)

[20] Nakajima, T., Koh, M., Synthesis of high crystalline carbon-nitrogen layered compounds by CVD using nickel and cobalt catalysts, Carbon 35 (2), pp. 203-208 (1997)

[21] Rümmeli, M.H., Kramberger, C., Grüneis, A., Ayala, P., Gemming, T., Büchner, B., Pichler, T., On the graphitization nature of oxides for the formation of carbon nanostructures, Chemistry of Materials 19 (17), 4105-4107 (2007)

[22] Volotskova, O., Levchenko, I., Shashurin, A., Raitses, Y., Ostrikov, K., Keidar, M., Single-step synthesis and magnetic separation of graphene and carbon nanotubes in arc discharge plasmas, Nanoscale 2 (10), 2281-2285 (2010)

[23] Li, B.-J., Kung, S.-C., Hsu, C.-M., Gao, J.-Y., Lai, H.-J., Preparation of a new carbon nanopartlcle by arc discharge, Materials Research Society Symposium Proceedings 822, art. no. S6.12, pp. 115-120 (2004)

[24] Fei Tan, K., Xu, J., Chang, J., Borgna, A., Saeys, M., Carbon deposition on Co catalysts during Fischer-Tropsch synthesis: A computational and experimental study, Journal of Catalysis 274 (2), 121-129 (2010)

[25] Swart, J.C.W., Van Steen, E., Ciobíč, I.M., Van Santen, R.A., Interaction of graphene with FCC-Co(111), Physical Chemistry Chemical Physics 11 (5), pp. 803-807 (2009)

[26] Nolan, P.E., Lynch, D.C., Cutler, A.H., Carbon deposition and hydrocarbon formation on group VIII metal catalysts, Journal of Physical Chemistry B 102 (21), 4165-4175 (1998)

[27] Parvizi, F., Teweldebrhan, D., Ghosh, S., Calizo, I., Balandin, A.A., Zhu, H., Abbaschian, R. Cabioc'h, T., Naudon, A., Jaouen, M., Thiaudiére, D., Babonneau, D., Cosputtering $\mathrm{C}-\mathrm{Cu}$ thin film synthesis: Microstructural study of copper precipitates encapsulated into a carbon matrix, Philosophical Magazine B: Physics of Condensed Matter; Statistical Mechanics, Electronic, Optical and Magnetic Properties 79 (3), pp. 501-516 (1999)

[28] Jee, A.-Y., Lee, M., Synthesis of two dimensional carbon sheets from adamantane, Carbon 47 (10), 2546-2548 (2009) 
[29] Bongiorno, G., Blomqvist, M., Piseri, P., Milani, P., Lenardi, C., Ducati, C., Caruso, T., Coronel, E., Nanostructured $\mathrm{CNx}(0<\mathrm{x}<0.2)$ films grown by supersonic cluster beam deposition, Carbon 43 (7) 1460-1469 (2005)

[30] Dmitry V. Kosynkin, Amanda L. Higginbotham, Alexander Sinitskii, Jay R. Lomeda, Ayrat Dimiev, B. Katherine Price, James M. Tour, Longitudinal unzipping of carbon nanotubes to form graphene nanoribbons, Nature 458, 872 (2009)

[31] Laurent Baraton, Zhanbing He, Chang Seok Lee, Jean-Luc Maurice, Costel Sorin Cojocaru, Anne-Franc, oise Gourgues-Lorenzon, Young Hee Lee and Didier Pribat, Synthesis of few-layered graphene by ion implantation of carbon in nickel thin films, Nanotechnology 22 (2011) 085601 (5pp)

[32] Slaven Garaj, William Hubbard, and J. A. Golovchenko, Graphene synthesis by ion implantation, Appl. Phys. Lett. 97, 183103 (2010)

[33] B.W. Mwakikunga, A. Forbes, E. Sideras-Haddad, R.M. Erasmus, G. Katumba, B. Masina, Int. J. Nanoparticles 1, 3 (2008)

[34] B.W. Mwakikunga, A. Forbes, E. Sideras-Haddad, C. Arendse, Nanoscale Res. Lett. 3, $372(2008)$

[35] M. Watanabe, H. Takamura, H. Sugai, Nanoscale Res. Lett. 4, 565 (2009)

[36] H. Hada, Y. Yonezawa, A. Yoshida, A. Kurakake, J. Phys. Chem. 80, 2728 (1976)

[37] K. Kurihara, J. Kizling, P. Stenius, J.H. Fendler, J. Am. Chem.Soc. 105, 2574 (1983)

[38] L. Bronstein, D. Chernshov, P. Valetsky, N. Tkachenko, H. Lemmetyinen, J. Hartmann, S. Forster, Langmuir 15, 83 (1999)

[39] J.A. Powell, S.R. Logan, J. Photochem. 3, 189 (1974)

[40] J. Pola, M. Marysko, V. Vorlicek, S. Bakardjieva, J. Subrt, Z. Bastl, A. Ouchi, J. Photochem. Photobiol. Chem. 199, 156 (2008)

[41] C. Liang, Y. Shimizu, M. Masuda, T. Sasaki, N. Koshizaki, Chem. Mater. 16, 963 (2004)

[42] Y. Ishikawa, K. Kawaguchi, Y. Shimizu, T. Sasaki, N. Koshizaki, Chem. Phys. Lett. 428, 426 (2006)

[43] J. Livage, Chem. Mater. 3, 578 (1991)

[44] A. Picard, I. Daniel, G. Montagnac, P. Oger, Extremophiles 11, 445 (2007)

[45] A.C. Ferrari, J. Robertson, Phys. Rev. B 64, 075414 (2001)

[46] R. Tenne, I. Margulis, M. Genut, G. Hodes, Nature 360, 444 (1992)

[47] J. Liu, D. Xue, Adv. Mater. 20, 2622 (2008)

[48] J. Liu, F. Liu, K. Gao, J. Wu, D. Xue, J. Mater. Chem. 19, 6073 (2009)

[49] G.T. Chandrappa, N. Stenou, S. Cassaignon, C. Bauvis, J. Livage, Catal. Today 78, 85 (2003)

[50] V.V. Ivanovskaya, A.N. Enyashin, A.A. Sofronov, Y.N. Makurin, N.I. Medvedeva, A.L. Ivanovskii, Solid State Commun. 126, 489 (2003)

[51] D. Riou, G. Ferey, J. Solid State Chem. 120, 137 (1995)

[52] B. W. Mwakikunga, A. Forbes, E. Sideras-Haddad, M. Scriba, E. Manikandan, Self Assembly and Properties of C:WO3 Nano-Platelets and C:VO2/V2O5 Triangular Capsules Produced by Laser Solution Photolysis, Nanoscale Res Lett. 5, 389 (2010) 


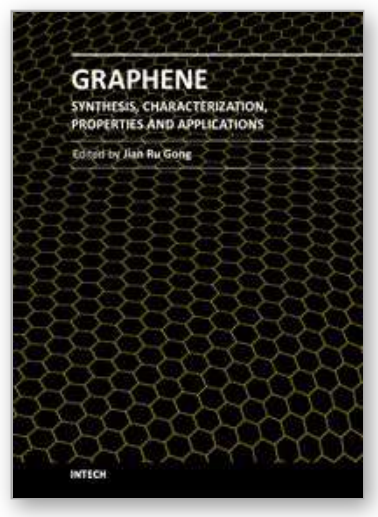

\author{
Graphene - Synthesis, Characterization, Properties and \\ Applications \\ Edited by Prof. Jian Gong
}

ISBN 978-953-307-292-0

Hard cover, 184 pages

Publisher InTech

Published online 15, September, 2011

Published in print edition September, 2011

The discovery of graphene has led to a deluge of international research interest, and this new material in the field of materials science and condensed-matter physics has revealed a cornucopia of new physics and potential applications. This collection gives a roughly review on the recent progress on the synthesis, characterization, properties and applications of graphene, providing useful information for researchers interested in this area.

\title{
How to reference
}

In order to correctly reference this scholarly work, feel free to copy and paste the following:

Bonex W Mwakikunga and Kenneth T Hillie (2011). Graphene Synthesis, Catalysis with Transition Metals and Their Interactions by Laser Photolysis, Graphene - Synthesis, Characterization, Properties and Applications, Prof. Jian Gong (Ed.), ISBN: 978-953-307-292-0, InTech, Available from:

http://www.intechopen.com/books/graphene-synthesis-characterization-properties-and-applications/graphenesynthesis-catalysis-with-transition-metals-and-their-interactions-by-laser-photolysis

\section{INTECH}

open science | open minds

\section{InTech Europe}

University Campus STeP Ri

Slavka Krautzeka 83/A

51000 Rijeka, Croatia

Phone: +385 (51) 770447

Fax: +385 (51) 686166

www.intechopen.com

\section{InTech China}

Unit 405, Office Block, Hotel Equatorial Shanghai

No.65, Yan An Road (West), Shanghai, 200040, China

中国上海市延安西路65号上海国际贵都大饭店办公楼 405 单元

Phone: +86-21-62489820

Fax: $+86-21-62489821$ 
(C) 2011 The Author(s). Licensee IntechOpen. This chapter is distributed under the terms of the Creative Commons Attribution-NonCommercialShareAlike-3.0 License, which permits use, distribution and reproduction for non-commercial purposes, provided the original is properly cited and derivative works building on this content are distributed under the same license. 